\title{
ANALISIS KELUHAN MUSCULOSKELETAL DISORDERS (MSDS) PADA KARYAWAN PT. CONTROL SYSTEM ARENA PARA NUSA
}

\author{
Nur Asniati Djaali ${ }^{1)^{*}}$, Meidy Putri Utami ${ }^{2)}$ \\ Program Studi S2 Kesehatan Masyarakat Universitas Mohammad Husni Thamrin \\ nurdjaali@gmail.com
}

\begin{abstract}
ABSTRAK
Musculoskleletal Disorders (MSDs) merupakan gangguan kesehatan yang sering dialami pekerja dengan berbagai jenis pekerjaan. Penggunaan komputer ketika bekerja dalam jangka waktu lama dan terus menerus, yang terlihat tidak berbahaya tidak menghilangkan kemungkinan pekerja terkena penyakit tersebut. Tujuan penelitian ini adalah untuk melihat faktor yang berhubungan dengan kejadian MSDs. Penelitian ini merupakan penelitian kuantitatif menggunakan desain kroseksional, dengan melibatkan 84 karyawan pada PT. Control System Arena Para Nusa Jakarta. Pengukuran MSDs dilakukan menggunakan metode Rapid Office Strain Assesment (ROSA). Hasil studi ini menunjukkan sebanyak 65,5\% karyawan mengalami keluhan MSDs. Hasil Uji Chi Square menunjukkan faktor ergonomi $\left(\mathrm{p}_{\mathrm{v}}=0,008\right)$ dan kebiasaan olahraga $\left(\mathrm{p}_{\mathrm{v}}=0,002\right)$ merupakan faktor yang berhubungan dengan terjadinya keluhan MSDs. Untuk mencegah atau mengurangi keluhan MSDs sebaiknya melakukan memodifikasi atau mengganti kursi yang ada dengan kursi yang lebih ergonomis serta adanya program otomatis matinya layar komputer apabila telah melewati batas waktu kerja tertentu agar karyawan melakukan peregangan dan istirahat. Mewajibkan karyawan untuk mengikuti salah satu program olahraga yang telah disediakan oleh perusahaan dengan tujuan agar terjaganya kesehatan para karyawan.
\end{abstract}

Kata kunci: Musculoskleletal Disorders, ROSA, Ergonomi, Msds

\section{PENDAHULUAN}

Proporsi Penyakit Akibat Kerja (PAK) menurut European Occupational Disease Statistic yaitu Musculoskeletal Disorders sebanyak 38,1\%, gangguan syaraf 20,9\%, gangguan pernapasan 14,3\%, organ sensorik $12,8 \%$, penyakit kulit 7,1\%, kanker 5\%, dan infeksi $0,5 .{ }^{1}$ Musculoskeletal Disorders mewakili 59\% dari keseluruhan catatan penyakit yang ditemukan pada tahun 2005 di Eropa. Komisi pengawas Eropa pada tahun 2005 menunjukan bahwa sebesar 49,9\% ketidakhadiran kerja lebih dari tugas hari dan sebesar 60\% kasus ketidakmampuan permanen dalam bekerja disebabkan oleh MSDs. Kasus MSDs di Korea mengalami peningkatan yang sangat tinggi dari 1.634 kasus pada tahun 2001 menjadi 5.502 kasus pada tahun $2010 .^{2}$

Profil Masalah Kesehatan Pekerja di Indonesia menunjukan bahwa sekitar 40,5\% penyakit yang diderita pekerja berhubungan dengan pekerjaannya. Gangguan kesehatan yang dialami pekerja menurut studi yang dilakukan terhadap 9.482 pekerja di 12 Kabupaten/Kita di Indonesia, umumnya berupa gangguan MSDs (16\%), Kardiovaskuler (8\%), gangguan saraf (6\%), gangguan pernapasan (3\%) dan gangguan THT $(1,5 \%){ }^{3}$

Penelitian sebelumnya yang dilakukan pada PT. Suryo Toto Indonesia ditemukan sebanyak $72,8 \%$ mengalami keluhan MSDs. ${ }^{4}$ Penelitian lainnya oleh Zar 2011 diketahui 72,9\% responden mengeluhkan musculoskeletal. Keluhan terbanyak dirasakan oleh responden pada bagian pantat dan punggung 
$(56,07 \%)$, pinggang $(51,40 \%)$, dan keluhan pada leher $(50,48 \%){ }^{5}$

Musculoskleletal Disorders (MSDs) merupakan gangguan kronik pada otot, tendon dan syaraf yang disebabkan oleh penggunaan tenaga secara repetitif, pergerakan yang cepat, penggunaan tenaga yang besar, kontak dengan tekanan, postur janggal atau ekstrim, getaran dan temperatur yang rendah., Masalah ini memberikan dampak kepada para pekerja dan juga pada pihak manajemen perusahaan ataupun pihak pemilik usaha, yaitu menurunnya produktivitas dan kualitas kerja, tingginya angka abseneisme dan turnover pada pekerja. Seringkali pekerja yang memiliki gangguan musculoskeletal harus kehilangan waktu dari pekerjaan untuk pulih kembali dan sulit untuk pulih total. ${ }^{8}$

PT. Control Systems Arena Para Nusa atau yang biasa disingkat dengan PTCS merupakan perusahaan swasta nasional yang didirikan sejak tahun 1980 dan bergerak di bidang Proses Instrumentasi, Kontrol, dan Fiscal Metering. Pada kantor pusat PTCS yang berada di Jakarta, pekerjaan terbanyak karyawan yaitu berhubungan dengan komputer. Walaupun terlihat nyaman dan bukan pekerjaan berat, bukan berarti tidak ada bahaya atau efek negatif yang mungkin dapat diterima oleh karyawan.

\section{METODE}

Penelitian ini merupakan penelitian kuantitatif menggunakan desain kroseksional. Penelitian ini dilakukan di PT Control System Arena Para Nusa yang melibatkan sebanyak 84 karyawan sebagai responden. Sampel dihitung berdasarkan rumus sample size estimasi proporsi dengan teknik sampling menggunakan simple random sampling. Penelitian dilakukan pada bulan Maret sampai Juni 2018.

Instrumen yang digunakan untuk mengukur MSDs adalah menggunakan Nordic Body Map (NBM) untuk mengetahui bagian tubuh yang dikeluhkan/nyeri, jenis keluhan, dan tingkat keluhan yang dirasakan. Untuk menilai resiko berdasarkan postur tubuh pekerja menggunakan metode Rapid Office Strain Assessment (ROSA), yaitu salah satu metode pada office ergonomis, dimana penilaiannya dirancang untuk mengukur risiko yang terkait dengan penggunaan komputer serta untuk menetapkan tingkat tindakan perubahan berdasarkan laporan dari ketidaknyamanan pekerja. Timbangan berat badan digunakan untuk mengukur berat badan responden, strature meter digunakan untuk mengukur tinggi badan responden. Sedangkan untuk pengukuran variabel lainnya menggunakan kuesioner yang berisi daftar pertanyaan mengenai factor resiko lainnya yang meliputi variabel usia, masa kerja, indeks massa tubuh, dan kebiasaan olahraga.

Data dianalisis menggunakan analisis deskriptif dan uji Chi-Square yang bertujuan untuk faktor yang berhubungan dengan MSDs. Selain itu juga menggunakan nilai Odd Ratio untuk melihat besarnya peluang terjadinya MSDs pada kelompok yang beresiko.

\section{HASIL}

Hasil analisis deskriptif menunjukkan bahwa sebagian besar responden merasakan keluhan MSDs yaitu 
sebanyak 55 responden (65.5\%). Sebanyak 28,6 \% responden yang berisiko dalam factor ergonomic berdasarkan metoda ROSA, 40,5\% responden berusia diatas 30 tahun, 45,2\% memiliki masa kerja diatas 5 tahun, 42,9\% responden memiliki IMT yang berisiko, dan 59,5\% memiliki kebiasaan olahraga yng kurang atau buruk.

Tabel 1 menunjukkan hasil analisis bivariat. Faktor ergonomi menggunakan metode ROSA, tingkat risiko yang didapatkan menunjukan adanya tingkat risiko rendah dan tingkat risiko sedang, dengan hasil perhitungan responden dengan tingkat risiko sedang 60 orang (71.4\%). Berdasarkan hasil uji statistik dengan menggunakan uji Chi-square diperoleh bahwa terdapat hubungan antara factor ergonomic dengan keluhan MSDs dengan $p$ value sebesar 0.008. Hasil analisis juga menunjukkan nilai OR pada karyawan yang memiliki faktor ergonomik berisiko sedang akan memiliki peluang untuk mengalami keluhan MSDs sebesar 4,2 kali lebih besar dibandingkan dengan karyawan yang memiliki factor ergonomic dengan risiko rendah.

Fator kebiasaan olahraga menunjukkan terdapatnya hubungan yang signifikan terhadap keluhan MSDs dengan besar $\mathrm{p}_{\text {value }}$ adalah 0,002 . Seorang yang memiilki kebiasaan olahraga kurang baik memilikirisiko untuk mengalami keluhan MSDs 5 kali lebih tinggi dibandingkan dengan seorang dengan kebiasaan olahraga yang cukup baik.

Terdapat sebanyak 70.6\% karyawan yang memiliki usia > 30 Tahun dan mengalami keluhan MSDs, dan sebanyak $62 \%$ karyawan yang memiliki usia $\leq 30$ Tahun mengalami keluhan MSDs. Hasil uji statistic menunjukkan tidak adanya hubungan antara faktor usia dengan keluhan MSDs. Untuk variabel masa kerja, sebanyak $71.1 \%$ karyawan termasuk dalam kategori dengan masa kerja $\geq 5$ tahun dan mengalami keluhan MSDs, dan sebanyak 60\% karyawan termasuk dalam kategori dengan masa kerja $<5$ tahun dan mengalami keluhan MSDs. Hasil uji statistic menunjukkan tidak terdapat hubungan antara faktor masa kerja yang dengan keluhan MSDs. Demikian pula halnya dengan variabel IMT, sebesar $66.7 \%$ masuk kedalam IMT kategori berisiko dan mengalami keluhan MSDs, sebanyak 64.6\% karyawan yang memiliki IMT kategori tidak berisiko dan mengalami keluhan MSDs. Hasil uji statistik menunjukkantidak terdapatnya hubungan antara faktor indeks masa tubuh yang dengan keluhan MSDs.

Pada variabel kebiasaan olahraga kurang terdapat sebanyak 40 orang (80\%) mengalami keluhan MSDs, serta karyawan yang memiliki kebiasaan olahraga cukup sebanyak 15 orang (44.1\%) dan mengalami keluhan MSDs. Dari hasil uji statistik didapatkan nilai probabilitas sebesar 0.002, sehingga dapat diketahui bahwa adanya hubungan antara faktor kebiasaan olahraga dengan keluhan MSDs pada karyawan di PT. Control Systems Arena Para Nusa. Serta memiliki nilai OR sebesar 5.067 yang berarti karyawan yang memiliki kebiasaan olahraga kategori kurang memiliki risiko keluhan MSDs sebanyak 5 kali lebih besar dibandingkan dengan karyawan yang memiliki kebiasaan olahraga kategori cukup. 


\section{PEMBAHASAN}

Musculoskeletal Disorders atau biasa disebut MSDs adalah sekumpulan gejala/gangguan yang berkaitan dengan jaringan otot, tendon, ligament, kartilago, sistem saraf, struktur tulang dan pembuluh darah. Hasil analisis menunjukkan sebesar 65,5\% karyawan pada PT. Control Systems Arena Para Nusa Mengalami keluhan MSDs. Dari hasil penelusuran lebih lanjut menggunakan instrumen Nordic Body Map (NBM) didapatkan bahwa karyawan mengalami keluhan pada bagian pinggang $12.43 \%$, leher bagian atas sebanyak $10.36 \%$, dan leher bagian bawah sebanyak 9.84\%. Penelitian ini sejalan dengan studi yang dilakukan oleh Gayo dan Cindyastira, yang menunjukkan keluhan tertinggi pada pekerja office terdapat pada bagian punggung dan pinggang, dan keluhan tertinggi kedua terdapat pada bagian leher atas. Keluhan pada pinggang serta anggota tubuh bagian atas disebabkan karena adanya pekerjaan posisi janggal yang dilakukan berulang-ulang, mengangkat beban yang berat serta postur tubuh tidak dapat menyesuaikan dengan posisi objek yang dikerjakan, sehingga tidak terlalu memperhatikan posisi kerja ergonomis. ${ }^{9,10}$

Tingkat risiko ergonomi pada penelitian ini diukur dengan menggunakan metode Rapid Office Strain Assesment (ROSA) untuk seluruh bagian tubuh dengan mempertimbangkan durasi, frekuensi dan postur tubuh. Tingkat risiko ergonomi kemudian dikategorikan menjadi 3 kategori, yaitu risiko rendah jika skor ROSA 1-3, risiko sedang jika skor ROSA 4-6, dan risiko tinggi jika skor ROSA > 7. Pekerja yang melakukan pekerjaan dengan posisi duduk biasanya bagian tubuh yang dikeluhkan pada bagian pinggang, punggung, dan leher. ${ }^{11}$ Keseimbangan dari postur tubuh perlu diperhatikan agar seseorang dapat bekerja dengan aman, nyaman dan tahan lama. Postur tubuh yang tidak seimbang dan berlangsung lama dalam jangka waktu yang lama akan mengakibatkan stress postural pada bagian tubuh tertentu. Sandaran kursi yang baik adalah yang dapat menyanggah seluruh bagian punggung, sehingga beban yang ditopang semakin sedikit. Sedangkan kondisi kursi mayoritas yang ada di kantor PTCS tidak menopang seluruh punggung, namun hanya sebagian punggung saja. Sehingga menyebabkan tekanan yang tidak merata yaitu hanya pada bagian punggung saja. ${ }^{5} 12$

Keluhan MSDs pertama biasanya dirasakan pada usia 30 tahun dan tingkat keluhan akan terus meningkat sejalan dengan bertambahanya usia. ${ }^{13}$ Hal ini terjadi karena usia setengah baya, kekuatan dan ketahanan otot manusia mulai menurun sehingga risiko terjadinya keluhan otot meningkat. Tidak sesuainya teori dan hasil penelitian yang dilakukan kemungkinan dikarenakan faktor usia bukanlah faktor utama yang menyebabkan keluhan MSDs, usia merupakan faktor kombinasi yang menyebabkan terjadin ya MSDs seperti LBP, CTS dan sebagainya. ${ }^{14}$ Artinya usia tidak bisa berdiri sendiri untuk mengakibatkan terjadinya gangguan MSDs tersebut, namun ada faktor-faktor lain yang mungkin lebih dominan. ${ }^{15}$

Masa kerja adalah lama waktu yang terhitung mulai pertama kali pekerja masuk ke kantor tersebut hingga penelitian ini berlangsung. Semakin lama masa kerja seseorang menyebabkan terjadinya kejenuhan pada 
daya tahan otot dan tulang secara fisik maupun secara psikis. Gangguan pada sistem Musculoskeletal hampir tidak pernah dirasakan secara langsung, tetapi merupakan hasil akumulasi dari paparan atau halhal besar yang terjadi secara terus menerus dalam waktu yang lama. Masa kerja seseorang merupakan faktor pendukung yang berkontribusi sebagai faktor yang cukup mempengaruhi terjadinya MSDs. ${ }^{14}$ Selain itu MSDs berdasarkan masa kerja seseorang erat kaitannya dengan jenis pekerjaan yang dilakukan, beban kerja yang berat tentunya akan lebih cepat menimbulkan dampak pada karyawan baik secara fisik maupun mental dibandingkan beban kerja yang ringan. Selain itu kemungkinan faktor usia berpengaruh, kebanyakan usia pegawai dibawah 35 tahun. ${ }^{13,16}$

Hubungan Indeks Massa Tubuh dengan keluhan muskuloskeletal yaitu semakin gemuk seseorang maka akan semakin besar risikonya akan keluhan muskuloskeletal. Hal ini disebabkan seseorang dengan kelebihan berat badan akan berusaha untuk menyangga berat badan dari depan dengan mengontraksikan otot punggung bawah. Apabila ini berlanjut terus menerus, akan menyebabkan penekanan pada bantalan saraf tulang belakang. ${ }^{17}$ Ketidakserasian hasil penelitian dengan teori mungkin dikarenakan sebagian besar data status gizi yaitu $59.53 \%$ masuk kedalam kategori normal. Selain itu mungkin karena timbulnya keluhan MSDs yang disebabkan oleh faktor-faktor lain seperti tingkat risiko ergonomi, kebiasaan olahraga, dan lain-lain. Pada umumnya keluhan otot jarang dialami oleh seseorang yang dalam aktivitas kesehariannya mempunyai cukup waktu untuk istirahat dan berolahraga. Sebaliknya, pekerja dengan keseharian kerja memerlukan tenaga besar dan tidak cukup istirahat akan lebih sering mengalami keluhan otot. $^{7}$ Bagi pekerja dengan kesegaran jasmani yang rendah, risiko keluhan menjadi tiga kali lipat dibandingkan yang memiliki kekuatan fisik tinggi. ${ }^{18}$

Kebiasaan olahraga yang baik dtemukan berhubungan dengan keluhan MSDs. Kurangnya aktifitas olahraga merupakan salah satu faktor risiko untuk terjadinya MSDs pada pekerja. Hasil penelitian ini menunjukkan bahwa pada seorang yang memiliki kebiasaan olahraga yang kurang baik akan berpeluang 5 kali untuk mengalami keluhan MSDs dibandingkan dengan seorang yang memiliki kebiasaan olahraga yang cukup baik. Hasil penelitian ini sejalan dengan studi yang dilakukan di Makassar bahwa kebiasaan olahraga menunjukkan hubungan terhadap keluhan MSDs. ${ }^{10}$ Demikian pula penelitian yang dilakukan oleh Zulfiqor (2010) dan Handayani (2011) yang menyatakan bahwa adanya hubungan antara kebiasaan olahraga dengan keluhan MSDs. ${ }^{417}$ Kurang atau tidak melakukan olahraga merupakan salah satu faktor risiko utama penyakit tidak menular diantaranya yang berhubungan dengan otot dan tulang. ${ }^{19}$ Pada umumnya keluhan otot jarang dialami oleh seseorang yang dalam aktivitas kesehariannya mempunyai cukup waktu untuk berolahraga dan sebaliknya, bagi orang yang bekerja dalam kesehariannya memerlukan banyak tenaga dan tidak cukup beristirahat akan lebih sering mengalami keluhan otot. Tingkat kesegaran tubuh yang rendah akan mempertinggi risiko kejadian terjadinya keluhan otot, sikap kerja yang dilakukan bergantung dari kondisi sistem kerja yang ada. ${ }^{12}$ 


\section{KESIMPULAN DAN REKOMENDASI}

Pada penelitian ini ditemukan keluhan musculoskeletal disorder (MSDs) pada karyawan PT. Control Systems Arena Para Nusa adalah sebanyak 65.5\%. Terdapat hubungan antara faktor ergonomi dan kebiasaan olahraga dengan terjadinya keluhan MSDs. Seorang karyawan yang memiliki posisi ergonomi berisiko akan berpeluang 4,2 kali untuk mengalami keluhan MSDs dibandingkan pada karyawam yang memiliki posisi ergonomic tidak berisiko. Seorang yang memiliki kebiasaan olahraga yang buruk akan berpeluang 5 kali lebih besar untuk mengalami keluhan MSDs dibandingkan pada karyawan yang melakukan aktifitas olaraga yang cukup baik.

Saran untuk menanggulangi terjadinya MSDs pada karyawan adalah melakukan modifikasi terhadap kursi yang digunakan menjadi kursi yang lebih ergonomi, yaitu yang memiliki sandara punggung full hingga punggung bawah, alas kaki, dan terdapat sandaran untuk tangan karyawan. Melakukan modifikasi terhadap layar komputer yang digunakan karyawan agar layar komputer dapat mengingatkan dan otomatis mati apabila karyawan telah melakukan kerja selama 2-3 jam dengan lama istirahat selama 5-10 menit. Melakukan senam sederhana yang disarankan oleh tim QHSE bagi karyawan untuk peregangan otot selama masa istirahat berlangsung. Selain itu, perusahaan sebaiknya mewajibkan karyawan untuk ikut senam pagi yang diadakan rutin dan difasilitasi oleh perusahaan.

\section{REFERENSI}

1. Report ERO. Europan Agency for Safety and Health at Work. Luxembourg: Publications Office of the European Union 2010.

2. ILO ILO. Keselamatan dan Kesehatan Kerja di Tempat Kerja. Jakarta: Departemen Kesehatan RI; 2013.

3. RI DK. Profil Masalah Kesehatan Pekerja di Indonesia Tahun 2005. Jakarta: Departemen Kesehatan RI; 2005.

4. Handayani W. Faktor-Faktor yang Berhubungan dengan Keluhan Musculoskeletal Disorders pada Pekerja di Bagian Polishing PT. Surya Toto Indonesia. Tbk Tangerang Tahun 2011. 2011.

5. Zar A. Faktor-faktor yang Berhubungan dengan Keluhan Muskuloskeletal pada Upper Limb Extremities Mahasiswa Ketika Proses Belajar Mengajar di Kelas di Fakultas Kedokteran dan Ilmu Kesehatan Universitas Islam Negeri Syarif Hidayatullah Jakarta Tahun 2012. 2012.

6. ACGIH. TLVs and BEIs. United States: Signature Publication; 2010.

7. Sonne M, Villalta DL, Andrews DM. Development and evaluation of an office ergonomic risk checklist: ROSA-Rapid office strain assessment. Applied ergonomics. 2012;43(1):98-108.

8. OSHA. Ergonomi : The Study of Work. US Department of Labor Occupational Safety and Health Administration. OSHA 31252002. 
9. Gayo I. Gambaran Sikap Kerja dan Keluhan Muskuloskeletal pada Penyortir Kopi di Industri Kopi Baburrayyan Takengon Aceh Tengah Tahun 2010. 2010.

10. Cindyastira D, Russeng SS, Wahyuni A. Intensitas Getaran dengan Keluhan Muskuloskeletal Disorders (Msds). Media Kesehatan Masyarakat Indonesia. 2016;10(4):234-40.

11. Ginanjar R, Fathimah A, Aulia R. ANALISIS RISIKO ERGONOMI TERHADAP KELUHAN MUSCULOSKELETAL DISORDERS (MSDs) PADA PEKERJA KONVEKSI DI KELURAHAN KEBON PEDES KOTA BOGOR TAHUN 2018. PROMOTOR. 2018;1(2):1249.

12. Lubis SRH. Analisis Faktor Risiko Ergonomi terhadap Keluhan Musculoskeletal Disorders (MSDs) pada Teller Bank. Jurnal Ilmu Kesehatan Masyarakat. 2018;7(02):63-73.

13. Marthin E, Kawatu P, Kandouw G. Hubungan Antara Umur, Lama Kerja, Dan Getaran Dengan Keluhan Muskuloskeletal Pada Supir Bus Bus Trayek Bitung-Manado di Terminal Tangkoko Bitung Tahun 2016. Jurnal. 2016.

14. Randang MJ, Kawatu PAT, Sumampouw OJ. Hubungan Antara Umur, Masa Kerja Dan Lama Kerja Dengan Keluhan Musculoskeletal Pada Nelayan Di Desa Talikuran Kecamatan Remboken Kabupaten Minahasa. Media Kesehatan. 2017;9(3).

15. Tarwaka. Ergonomi Industri : Dasar-dasar Pengetahuan Ergonomi dan Aplikasi di Tempat Kerja. Solo: Harapan Press; 2015.

16. Rivai WT, Jayanti S. Hubungan Tingkat Risiko Ergonomi Dan Masa Kerja Dengan Keluhan Muskuloskeletal Pada Pekerja Pemecah Batu. Jurnal Kesehatan Masyarakat (e-Journal). 2014;2(3):227-31.

17. Zulfiqor MT. Faktor-faktor yang berhubungan dengan keluhan musculosletal disorders pada welder di bagian fabrikasi PT. Caterpillar Indonesia. 2010.

18. Suriyatmini S. Tinjauan Faktor Risiko Ergonomi Terhadap Keluhan Muskuloskeletal pada Aktivitas Manual Handling pada Pekerja di Bagian Produksi PTMI Tahun 2010. Depok: Universitas Indonesia; 2010.

19. Bustan. Epidemiologi Penyakit Tidak Menular. Jakarta: Rineka Cipta; 2007. 


\section{LAMPIRAN}

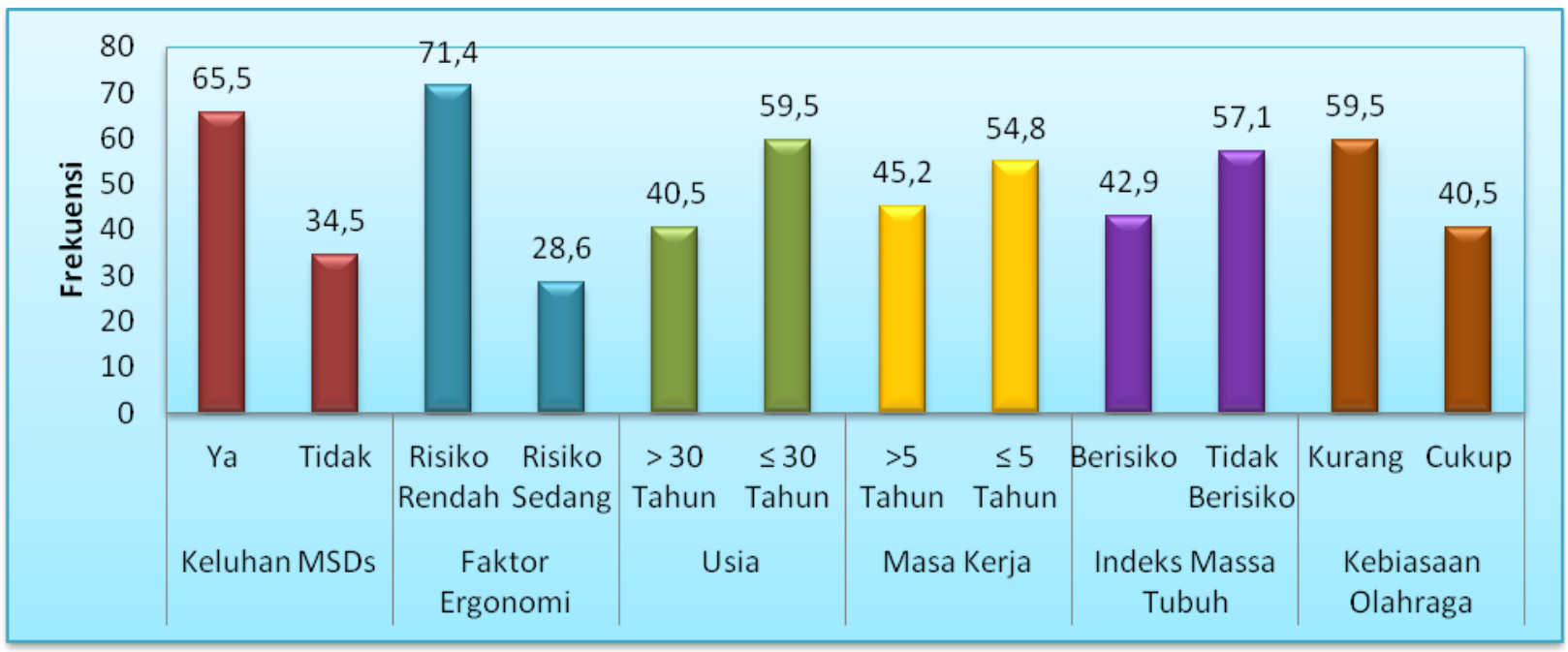

Gambar 1. Deskripsi Variabel Keluhan MSDs, Faktor Ergonomi, Usia, Masa Kerja, IMT, dan Kebiasaan Olahraga

Tabel 2. Analisis Hubungan antara Faktor Ergonomi, Usia, Masa Kerja, IMT, dan Kebiasaan Olahraga dengan Keluhan MSDs

\begin{tabular}{|c|c|c|c|c|c|c|c|}
\hline & & & Keluh & MS & & & \\
\hline & riable & Ada $\mathrm{K}$ & than & & $\begin{array}{l}\text { Ada } \\
\text { an }\end{array}$ & $\mathbf{P}_{\text {value }}$ & $\begin{array}{c}\text { OR } \\
\text { CI 95\% }\end{array}$ \\
\hline & & $\mathrm{n}$ & $\%$ & $\mathrm{n}$ & $\%$ & & \\
\hline & Risiko Sedang & 45 & 75 & 15 & 25.4 & & 4.200 \\
\hline & Risiko Rendah & 10 & 41.7 & 14 & 58.3 & $\delta$ & $1.545-11.417$ \\
\hline Ucia & $>30$ Tahun & 24 & 70.6 & 10 & 29.4 & 0562 & 1.471 \\
\hline Usia & $\leq 30$ Tahun & 31 & 62 & 19 & 38 & 0.505 & $0.579-3.739$ \\
\hline Mos & $\geq 5$ Tahun & 27 & 71.1 & 11 & 28.9 & 155 & 1.578 \\
\hline ivisa nefja & $<5$ Tahun & 28 & 60.9 & 18 & 29.1 & $0.7 J 5$ & $0.630-3.950$ \\
\hline MTT & $\begin{array}{l}\text { Berisiko } \\
(\text { IMT > 25) }\end{array}$ & 24 & 66.7 & 12 & 33.3 & 00 & 1.097 \\
\hline IMI & $\begin{array}{l}\text { Tidak Berisiko } \\
(\text { IMT } \leq 24)\end{array}$ & 31 & 64.6 & 17 & 35.4 & 1.000 & $0.441-2.728$ \\
\hline Kebiasaan & Kurang & 40 & 80 & 10 & 20 & & 5.067 \\
\hline Olahraga & Cukup & 15 & 44.1 & 19 & 55.9 & & 1.9 \\
\hline
\end{tabular}

